\title{
Religion and the attentional blink: depth of faith predicts depth of the blink
}

\author{
Lorenza S. Colzato' Bernhard Hommel' and Kimron L. Shapiro ${ }^{2 *}$ \\ Cognitive Psychology Unit and Leiden Institute for Brain and Cognition, Leiden University, Leiden, Netherlands \\ School of Psychology, Bangor University, Bangor, UK
}

Edited by:

Brad Wyble, Syracuse

University, USA

Reviewed by:

Mark Nieuwenstein,

University of Groningen, Netherlands Sander Martens,

University of Groningen, Netherlands

Paul E. Dux, University of Queensland,

Australia

\section{${ }^{*}$ Correspondence:}

Kimron L. Shapiro,

School of Psychology, Bangor

University, Adeilad Brigantia, Penrallt

Road, Gwynedd LL57 2AS, UK.

e-mail:k.shapiro@bangor.ac.uk
Religion is commonly defined as a set of rules, developed as part of a culture. Here we provide evidence that practice in following these rules systematically changes the way people allocate their attention, as indicated by the attentional blink (AB), a deficit in reporting the second of two target stimuli presented in close succession in a rapid sequence of distracters. We provide evidence that Dutch Calvinists and Atheists, brought up in the same country and culture and controlled for race, intelligence, mood, personality traits, and age, differ with respect to the amount of resources invested into processing $A B$ targets. Calvinists showed a larger $A B$ than Atheists, which is consistent with the notion that people's attentional processing style reflects biases rewarded by their religious beliefs.

Keywords: attentional blink, religion, attention

\section{INTRODUCTION}

Religion is commonly defined as a set of beliefs (a sort of framework) developed as part of a culture, which gives practitioners the experience that their life is meaningful. The idea that cultural experience might affect our perception and attention has been suggested by studies on cultural differences. For instance, Masuda and Nisbett (2001) observed that people growing up in Asian cultures exhibit a more holistic perceptual style (i.e., are more responsive to the global than to local features of visual objects or scenes) than people growing up in the North American culture. Westerners seem to focus on salient objects while East Asians attend more to the relationships between objects and background elements or context (Nisbett and Masuda, 2003; Nisbett and Miyamoto, 2005). This fits with the observation that East Asians allocate their attention more broadly across space than do Americans (Boduroglu et al., 2009). Researchers attribute these differences to culturally guided learning experience associated with selective reward for responses and actions that reflect culturally important values. The idea is that Western cultures often emphasize the individual and individual goals and needs, whereas Eastern Asian cultures emphasize the importance of the group and the social embedding of the individual in the group context (Nisbett and Miyamoto, 2005).

Even though culture apparently is an important determinant of inter-individual and inter-group differences, the cultural context is very hard to define (Colzato et al., in press). For instance, many intercultural comparisons of what is considered "Western" and "EasternAsian" cultures have evaluated US Americans in relation to Japanese. US Americans are composed of various cultural and national backgrounds, ranging from countries with particularly individualistic cultures, like the United Kingdom and the Netherlands, to countries with a particularly strong emphasis on collectivism, such as Greece and Mexico (cf., Hofstede, 2001). Japan, in contrast, is one of the Asian countries with the most individualistic culture. Thus it seems difficult to capture the essence of a culture by studying citizens of a particular country (which often live and represent different cultures) and to generalize from one country to its regional neighbors (e.g., to China, which is considered much more collectivistic than Japan; cf., Hofstede, 2001). In the absence of an unequivocal and straightforward definition of what a culture is and what it implies, it is difficult to derive clear-cut predictions of how culture might affect human cognition. Social systems that seem to be better suited for that purpose are religions (Colzato et al., in press). Even though not all religions are institutionally organized, regulated, and constrained by specific rules, a number of influential and widespread religions are, such as Judaism, Christianity, and Islam. At least for these religions it is thus possible to define with reasonable precision what rules and expectations the behavior of a believing member would have to meet.

Like cultures, religions differ with respect to the emphasis they put on the importance and responsibility of the individual versus the group. Accordingly, one could expect that religious practice should have a systematic impact on cognitive processes. Indeed recent observations are consistent with this expectation. Colzato et al. (2008c) compared Dutch neo-Calvinists and Atheists, brought up and living in the same country and controlled for various variables, in their performance on the global-local task (Navon, 1977) - a task that has been used in many cultural studies (e.g., Masuda and Nisbett, 2001). In this task, participants are presented with large rectangles and squares made of either smaller rectangles or smaller squares, and they carry out speeded choice responses to the shape of either the global figure or its local elements. Both neo-Calvinists and Atheists responded faster to the global than the local shapes, thus producing the well-known global-precedence 
effect (i.e., people see the forest before the trees: Navon, 1977). However, Calvinists showed a significantly less pronounced global precedence effect than Atheists. Given that neo-Calvinism is based on the so-called pillar concept of human society - where everyone should mind his/her own business and not judge others (cf., Bratt, 1998) - this outcome pattern was predicted: learning to systematically neglect one's broader social context to at least some degree should systematically shift the attentional focus from the context to the local detail.

Continuous exercise in controlling one's attention accordingly, in order to produce behavior that is rewarded by one's peer group, can be expected to establish "default values" used for attentional control settings that generalize to non-religious contexts (Hommel and Colzato, 2010). In other words, religious practice that systematically directs attention to local, rather than global, information might induce a chronic bias towards local processing. If so, one would expect that religions emphasizing the global social context, such as Judaism and Catholicism, induced a comparatively more global attentional bias. The recent study of Colzato et al. (in press) provides evidence that this is indeed the case: Italian Roman Catholics and Israeli Orthodox Jews showed a larger global precedence effect than Italian and Israeli seculars (baptized individuals who are not concerned with or devoted to religion), respectively. Hence, it is not just religious belief that matters (as argued by McCullough and Willoughby, 2009) but religious practice that has a specific impact on attentional control.

Although it is important to demonstrate that religion affects performance in a global-local task - the preferred diagnostic of the reviewed inter-cultural studies - it is even more important to demonstrate that the impact of religion affects attentional control more broadly. Toward this goal the present study was designed to test whether religion would not only affect the relative allocation of attention to the global versus local elements of hierarchically constructed stimuli, as assessed by the global-local task, but also impact the allocation of attention. A widely accepted tool to assess the allocation of attention over time is the so-called attentional blink (AB) task (Raymond et al., 1992). The AB occurs if two masked (or otherwise difficult to identify) target stimuli appear in close temporal proximity, such as in tasks using rapid serial visual presentation (RSVP): Whereas the first target (T1) is typically easy to report accurately, report of the second target (T2) is dramatically impaired if it follows T1 within 100-500 ms.

The most prominent capacity-limited account of $\mathrm{AB}$ refers to limited attentional resources (Chun and Potter, 1995; Jolicoeur and Dell'Acqua, 1998; Vogel et al., 1998; for a recent review, see Dux and Marois, 2009). According to these theories the AB is due to some sort of processing bottleneck: reporting a stimulus presupposes that its sensory representation is transferred to, and consolidated in WM, a process that is assumed to draw on attentional resources that are occupied for processing T1. In particular, Dux and Marois (2009) suggested that $\mathrm{AB}$ arises from attentional demands of T1 for selection, working memory encoding, episodic registration, and response selection, which prevents this high-level central resource from being applied to T2 at short T1-T2 lags.

Even though the $\mathrm{AB}$ is a robust phenomenon, there is mounting evidence for the role of strategic-, experience-related individual differences in modulating the severity of the AB. For instance, performance on T2 increases, sometimes even dramatically, when $\mathrm{T} 1$ and $\mathrm{T} 2$ are presented in a longer sequence of multiple targets (Di Lollo et al., 2005), if participants are assuming a relaxed attitude towards the task (Olivers and Nieuwenhuis, 2005), or if they are monolingual, rather than bilingual (Colzato et al., 2008a). In particular, Dale and Arnell (2010) found a negative correlation between global precedence and $\mathrm{AB}$ magnitude: people who have a disposition towards processing local, rather than global information, showed a greater $\mathrm{AB}$ magnitude. These observations suggest that individuals can exert control over the allocation of attention when processing targets. Indeed, electrophysiological and magnetoencephalographic markers of attentional processes were found to be very sensitive to experimental manipulations of participants' expectations regarding the timing and probability of target presentations in AB tasks (Martens and Johnson, 2005; Gross et al., 2006; Martens et al., 2006b; Akyürek et al., 2007). In addition, Shapiro et al. (2006) provided evidence that the individual size of the $\mathrm{AB}$ is predicted by the amount of attentional resources devoted to T1 processing (as indicated by the individual amplitude of the M3, the magnetoencephalographic equivalent of the electrophysiological P3). Interestingly, even though more resources were allocated to T1, T1 accuracy did not improve, suggesting that humans may overinvest attentional resources into $\mathrm{T} 1$ processing, in turn impairing T2 performance (Olivers and Nieuwenhuis, 2005, 2006; Taatgen et al., 2009). This model is consistent with the findings from other studies on individual differences, which consistently show effects on T2 but not T1 report (e.g., Martens et al., 2006a; Colzato et al., 2007, 2008a,b; Martens and Valchev, 2009; Dale and Arnell, 2010).

How can the observed individual differences be explained and what would the explanation imply for the possible impact of religion on attentional control? Consider the typical way neural decision-making is modeled. Making a decision between the alternatives $\mathrm{A}$ and $\mathrm{B}$ - be that responses to perform or stimulus representations to select for further processing - is commonly assumed to involve competition between the representations of the alternatives, as indicated by the mutual inhibitory links in Figure 1, and some sort of top-down support for the alternative that fits the current goals best (for a review, see Bogacz, 2007). If we follow the widespread assumption that experience and practice operates on the associations between cognitive representations rather than on the representations themselves (Hebb, 1949), this setup leaves two, not mutually exclusive types of associations that experience could modify: the strength to which top-down operating systems bias decision-making towards the most goalconsistent alternative (connection 1 in Figure 1) and the strength of the inhibitory links between the alternatives (connection 2). Having participants to relax (Olivers and Nieuwenhuis, 2005), to attend to a longer series of sequential targets (Di Lollo et al., 2005), or to meditate (Slagter et al., 2007) is likely to reduce the strength of top-down support for one particular target and/or the degree of mutual inhibition between alternatives. This would amount to spreading attentional resources more equally among competing candidates, which would mean that selecting A would lead to less inhibition of B. If we consider T1 and a temporally close T2 (just as a distractor) as competitors (an assumption that is suggested by findings of Potter et al., 2002; Hommel and 


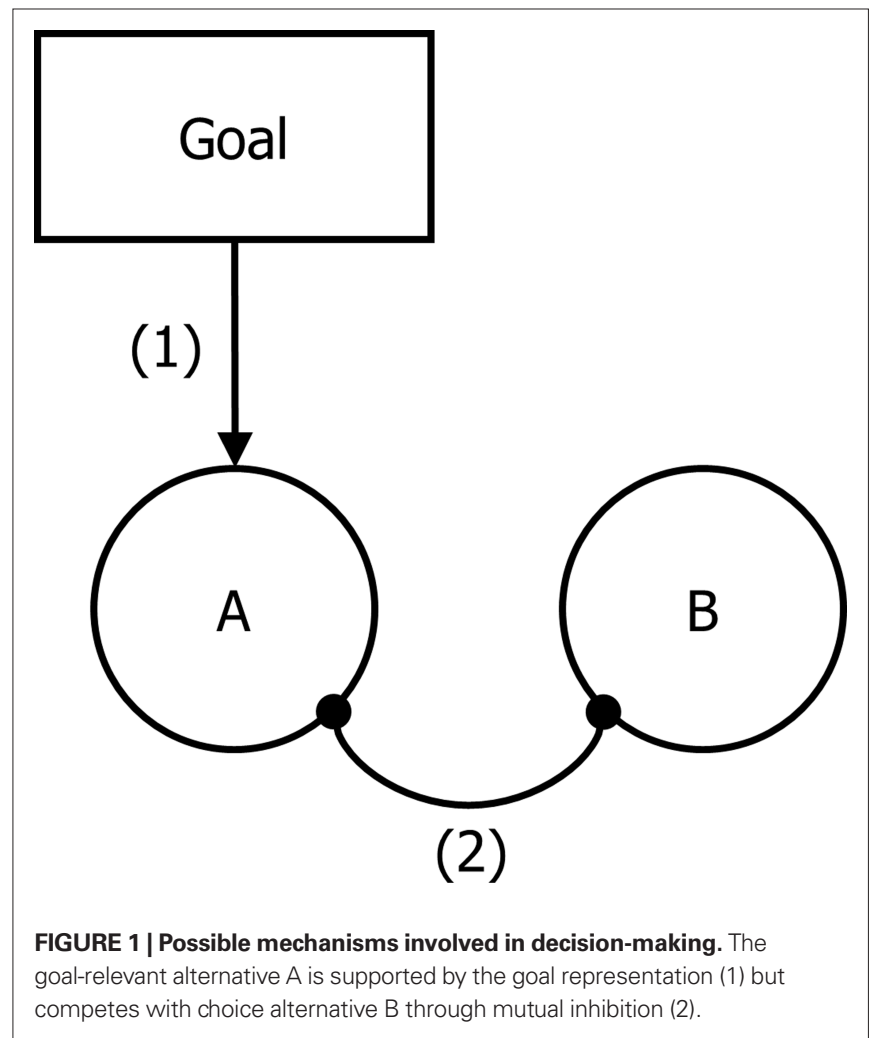

Akyürek, 2005), this scenario would correctly predict that T2 processing suffers less under these conditions, so that the $A B$ should be indeed reduced.

Extending this logic to practice suggests that being rewarded for behavior that relies on a particular configuration of top-down support and/or mutual inhibition between alternatives might induce a chronic bias towards this configuration. Evidence for this possibility comes from research on the cognitive effects of bilingualism. Other than monolingual, bilinguals and multilinguals are continuously facing the problem of cognitively keeping the languages they master apart, so to prevent mixing up words from different languages in the same sentence or utterance (Bialystok and Craik, 2010). Colzato et al. (2008a) suggested that this might lead to a relatively "exclusive" configuration of attentional control parameters, which amounts to a relatively strong top-down support for words from the currently spoken language and relatively strong local inhibition of words from other languages. If that configuration would become chronic, so the idea of Colzato et al. (2008a), it should generalize to other tasks, such as the AB task. An "exclusive" configuration would then be expected to lead to stronger inhibition of competitors of $\mathrm{T} 1$ - such as a temporally close $\mathrm{T} 2$. This predicts a stronger $\mathrm{AB}$ in bilinguals than in monolinguals, which was exactly the pattern that Colzato et al. (2008a) observed. Applying these considerations to Calvinists would result in exactly the same prediction: If we consider that Calvinism favors a local attentional focus over the processing of the broader context and if we assume that this induces a chronic, generalizable bias towards a more "exclusive" attentional control configuration, Calvinists should show a deeper $\mathrm{AB}$. We tested this prediction by comparing Calvinists and Atheists in a standard $A B$ paradigm.
Table 1 | Demographic characteristics of participants.

\begin{tabular}{|c|c|c|}
\hline Sample & Calvinists & Atheists \\
\hline $\operatorname{Sex} n(M: F)^{n s}$ & $20(15: 5)$ & $20(10: 10)$ \\
\hline Age (years) ns & $22.7(3.6)$ & $21.4(2.5)$ \\
\hline Raven $\mathrm{IQ}^{\text {ns }}$ & $120.5(3.2)$ & $120.2(2.7)$ \\
\hline \multicolumn{3}{|l|}{ AFFECT } \\
\hline Arousalns $^{\mathrm{n}}$ & $5.9(1.2)$ & $6.2(1.6)$ \\
\hline Moodns & $6.3(1.3)$ & $6.5(1.3)$ \\
\hline \multicolumn{3}{|l|}{ PERSONALITY } \\
\hline Extraversion ${ }^{\text {ns }}$ & $9.3(2.7)$ & $9.3(2.7)$ \\
\hline Psychotism ${ }^{\text {ns }}$ & $2.4(1.5)$ & $3.2(2.9)$ \\
\hline Neuroticism ${ }^{\text {ns }}$ & $4.9(2.8)$ & $5.1(2.8)$ \\
\hline Baptized (or similar) & $20(0)$ & $0(0)$ \\
\hline Daily prayers & $4.1(1.1)$ & $0(0)$ \\
\hline Weekly church visits & $1.8(0.4)$ & $0(0)$ \\
\hline
\end{tabular}

Standard deviations in parentheses. ns, non-significant difference.

\section{MATERIALS AND METHODS PARTICIPANTS}

The sample included 40 healthy subjects ( 25 male and 15 female) between 18 and 30 years of age. Half of the participants reported to be Calvinists (active members of the "Gereformeerde Gemeenten" and "Gereformeerde Vrijgemaakt" Church) and the other half to be Atheists (non-baptized). Members of the two groups were matched for race (100\% Caucasian), culture (100\% Dutch), age, sex, and IQ (measured by Raven's standard progressive matrices, SPM), educational style (Dutch VWO) and socio-economic situation (see Table 1). Participants were recruited by advertisements and snowball technique. Written informed consent was obtained from all participants after the nature of the study was explained to them; the protocol and the remuneration arrangements of 8 Euro was approved by the institutional review board (Leiden University, Institute for Psychological Research).

\section{APPARATUS AND STIMULI}

The experiment was controlled by a Targa Pentium III computer. All stimuli were presented in a resolution of $800 \times 600$ pixels in 16-bit color on a $17^{\prime}$ CRT refreshing at $100 \mathrm{~Hz}$. Participants were seated at a viewing distance of about $50 \mathrm{~cm}$. The fixation mark ("+"), as well as all RSVP items were presented centrally in black on a gray background (RGB 128, 128, 128). Each item was set in 16 point Times New Roman font. RSVP items included letters and digits. Letters were drawn randomly without replacement from the alphabet. Digits were drawn randomly from the set 1-9.

\section{PROCEDURE AND DESIGN}

All participants were tested individually and completed the intelligence test, the affect grid, the Eysenck's personality questionnaire (EPQ-RSS) and the RSVP experiment.

Individual IQ was determined by means of a 30-min reasoningbased intelligence test (Raven's SPM; Raven et al., 1988). The SPM assesses the individual's ability to create perceptual relations and to reason by analogy independent of language and formal schooling; it is a standard, widely used test to measure Spearman's $g$ factor and of fluid intelligence in particular. 
The affect grid is a single-items scale that measures affect along the dimensions of unpleasant/pleasant feelings and arousal/sleepiness (Russell et al., 1989). We used the affect grid in order to control for mood and arousal given that these factors have been shown to influence the $\mathrm{AB}$ phenomenon: $\mathrm{T} 2$ accuracy was highest for participants with low arousal and negative affect (Jefferies et al., 2008).

Participants were asked to put a mark in the grid in order to indicate their feelings at the present moment. The vertical dimension represented the degree of arousal versus sleepiness while the horizontal dimension represents unpleasant versus pleasant feelings.

The EPQ-RSS questionnaire consists of 48 yes/no questions that measure extraversion, neuroticism and psychoticism traits of personality (Eysenck et al., 1985). We controlled for personality traits because it has been shown that more extravert individuals tend to show an enhanced global attentional scope compared to neurotic individuals (Kossowksa and Necka, 1994).

In the RSVP task adopted from Colzato et al. (2007), participants had to identify and report two digits (T1 and T2) presented in a rapid stream of letter distractors. After reading the instructions, which included a slow demonstration of the RSVP, and indicating to have fully understood the task, participants were required to undergo 24 trials of training. If more than $50 \%$ of the responses were incorrect during the training, the training part was automatically restarted. A fixation “+” sign, which was shown for $2000 \mathrm{~ms}$, marked the beginning of each trial. After a blank interval of $250 \mathrm{~ms}$, the RSVP commenced, consisting of 20 items with a duration of $70 \mathrm{~ms}$ each and an inter-stimulus interval of $30 \mathrm{~ms}$.

The occurrence of $\mathrm{T} 1$ in the stimulus stream was varied randomly between positions 7,8 , and 9 to reduce the predictability of first target onset. T2 was presented directly after T1 (lag 1), or after another 2, 4, or 7 distracters (lag 3, 5, and 8, respectively), see Figure 2. Both targets were to be reported directly (order of report was not considered) after the RSVP - the question being "which two targets did you see?"- by pressing the corresponding digit keys. A full experimental session lasted $10 \mathrm{~min}$ and contained one block of 144 trials (three locations of $\mathrm{T} 1 \times$ four lags $\times 12$ repetitions).

\section{STATISTICAL ANALYSIS}

Independent samples $t$-tests were performed to test age, mood, personality traits, and IQ differences between the groups. T1 and T2 accuracy data were submitted to separate ANOVAs with lag $(1,3,5$, and 8 ) as a within-participants factor and Group (Calvinists versus Atheists) as a between-participant factor. T2 accuracy was based only on those trials in which T1 was correctly reported (T2|T1). To test whether the $\mathrm{AB}$ magnitude (measured as T2|T1 at Lag 8 minus T2|T1 at Lag 3) is proportional to the religious practice we computed Pearson correlation coefficients between the $\mathrm{AB}$ magnitude, daily prayers and weekly church visit. A significance level of $p<0.05$ was adopted for all statistical tests.

\section{RESULTS AND DISCUSSION}

No significant group differences were obtained for age, mood, personality traits and IQ, see Table 1.

T1 accuracy is shown in Figure 3. The ANOVA with lag as withinparticipant factor showed a significant lag effect, $F(3,114)=24.47$, $p<0.0001, \mathrm{MSE}=0.002, \eta^{2} p=0.39$. As Figure 3 shows, this effect was due to a reduction in performance at Lag 1 , i.e., when

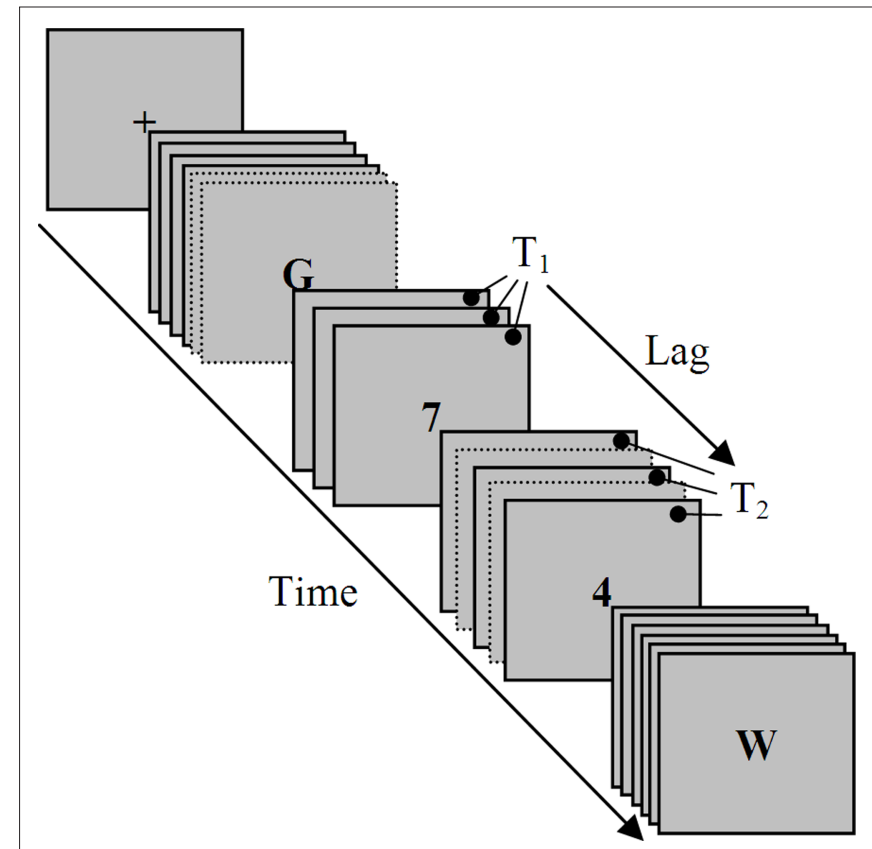

FIGURE 2 | Example of an RSVP trial. On every trial, 20 items were presented at the center of the screen, preceded by a 2,000-ms fixation cross. Most of the items were letters, presented for $70 \mathrm{~ms}$ each and followed by a 30-ms blank. Participants had to detect two target numbers (T1 and T2) among the items. T1 and T2 were separated by one, three, five, or eight non-target items, defining the lag. T1 was presented at position 7, 8, and 9 of the stimulus stream.

T2 immediately followed T1. This pattern is often observed if T1 and T2 belong to the same category (e.g., digits) and satisfy the same selection criteria, and when the presentation rate is fast. These conditions are thought to increase the competition between $\mathrm{T} 1$ and $\mathrm{T} 2$ representations if they occur close in time, with $\mathrm{T} 2$ outperforming T1 more often (Potter et al., 2002; Hommel and Akyürek, 2005; Colzato et al., 2007). Consistent with previous observations (Colzato et al., 2008a; Dale and Arnell, 2010), Group did not affect T1 performance, $F(3,114)=1.57, p=0.21$, MSE $=0.002$, $\eta^{2} p=0.04$.

More importantly, the ANOVA of conditional T2 accuracy $(\mathrm{T} 2 \mid \mathrm{T} 1)$ revealed a significant lag effect, $F(3,114)=145.63$, $p<0.0001, \mathrm{MSE}=0.004, \eta^{2} p=0.79$, indicating a marked $\mathrm{AB}$ with good performance at Lag 1 (Lag-1 sparing, Visser et al., 1999) and a considerable attenuation at Lags 3 and 5 (see Figures 3 and 4 for individual AB magnitude). As predicted, Group impacted the blink size, as indicated by a two-way interaction between group and lag, $F(3,114)=5.41, p<0.05$, MSE $=0.004, \eta^{2} p=0.12$ : Calvinists showed a greater $\mathrm{AB}$ magnitude than Atheists. Moreover, daily prayers positively correlated with $\mathrm{AB}$ magnitude, $r(20)=0.514$ $p<0.05$, while weekly church visit even though it followed the same trend, did not. Hence, more daily prayers are associated with greater AB magnitude, see Figure 5.

\section{CONCLUSIONS}

The aim of this study was to investigate whether Calvinists and Atheists differ in the way they allocate their attention, as revealed by a task known to index the allocation of attention over time. 

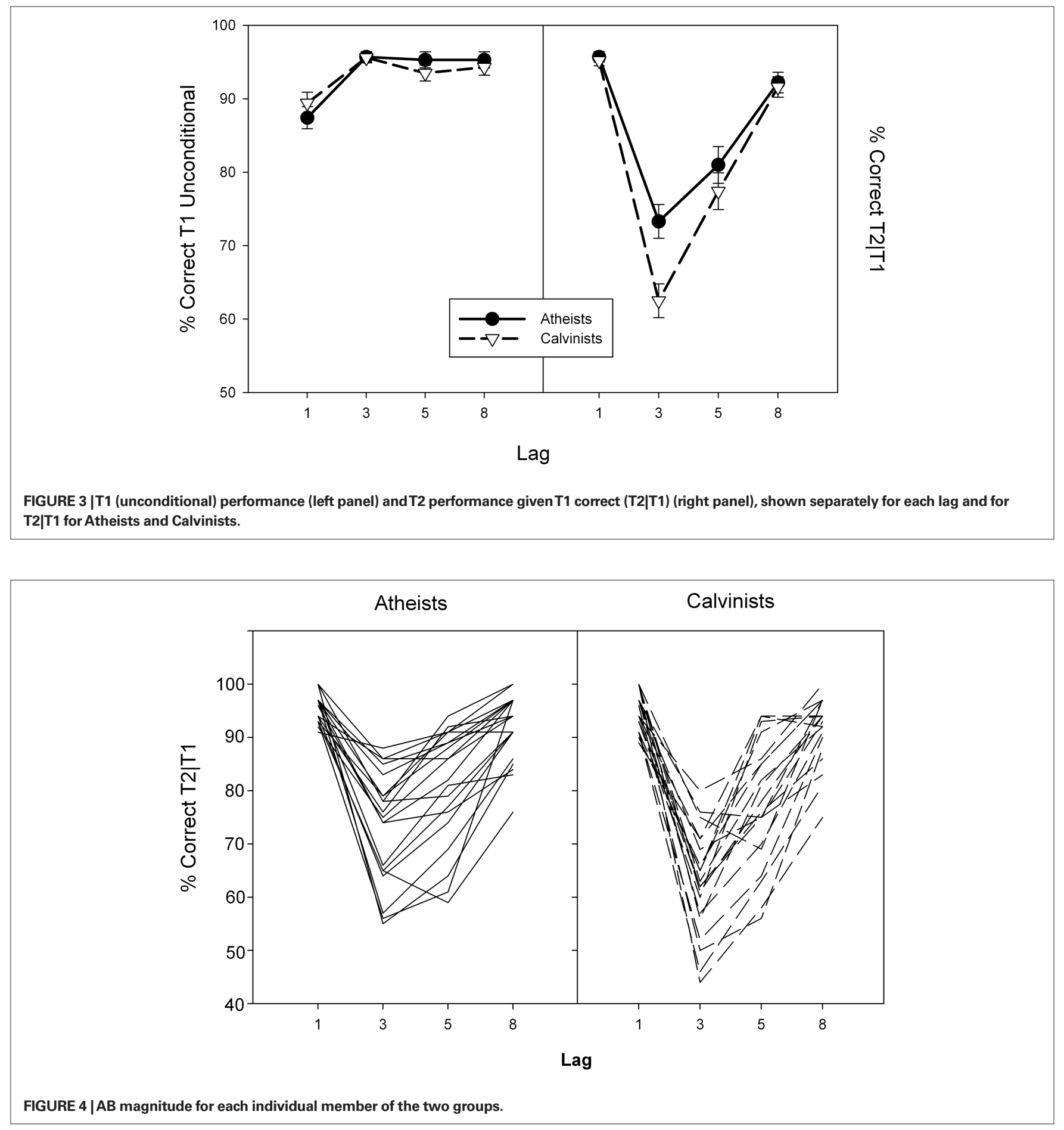

As predicted, the $\mathrm{AB}$ phenomenon was modified as a function of religious belief: Calvinists showed a more pronounced $\mathrm{AB}$ than Atheists. We have argued that becoming a good Calvinist involves adopting behavior that conforms to Calvinist rules and expectations, which is likely to be achieved by focusing on a narrower, as opposed to broader context. This, we assume, creates a chronic bias in an underlying attentional control setting, in turn generalizing to a style of information processing in cognitive tasks (Colzato et al., 2008c; Colzato et al., in press; Hommel and Colzato, 2010). As described in section "Introduction", this processing style was predicted to result in a larger blink in Calvinists, as our findings demonstrate. Moreover, our results are in line with the study by Dale and Arnell (2010), who found that individuals who have a disposition towards processing local rather than global information, as also in the case of Calvinists (Colzato et al., 2008c; Colzato et al., in press), showed a greater $\mathrm{AB}$ magnitude. 


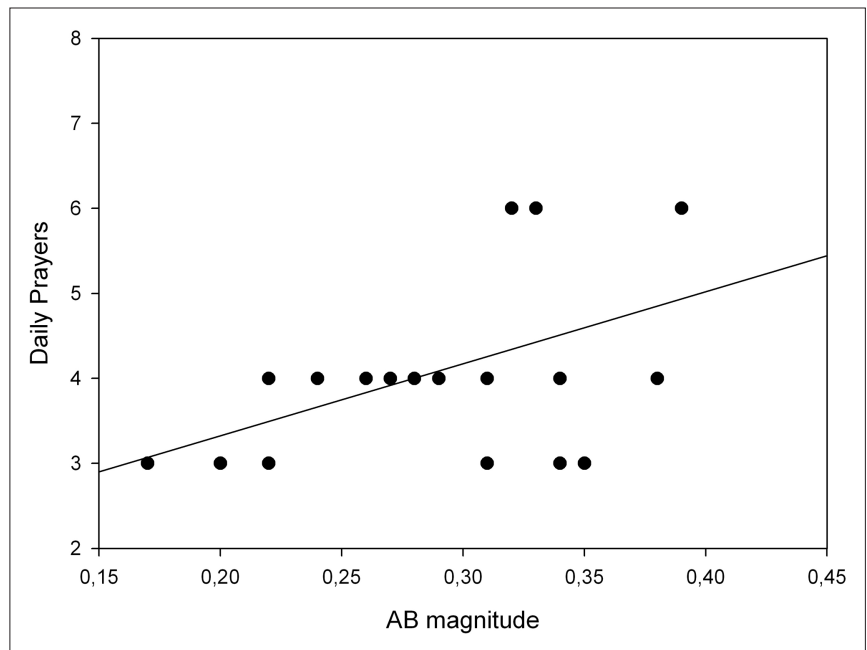

FIGURE 5 | Scatter plots of the relationships between $A B$ magnitude and daily prayers.

We recognize the alternative possibility that it is not religion, per se, which is responsible for the obtained difference but some other motivational, working memory capacity, video-game practice, social, or personality characteristic that is correlated with religion. For

\section{REFERENCES}

Akyürek, E. G., Riddell, P. M., Toffanin, P., and Hommel, B. (2007). Adaptive control of event integration: evidence from event-related potentials. Psychophysiology 44, 383-391.

Bialystok, E., and Craik, F. I. M. (2010). Cognitive and linguistic processing in the bilingual mind. Curr. Dir. Psychol. Sci. 19, 19-23.

Boduroglu, A., Shah, P., and Nisbett, R.E. (2009). Cultural differences in allocation of attention in visual information processing. J. Cross Cult. Psychol. 40, 349-360.

Bogacz, R. (2007). Optimal decisionmaking theories: linking neurobiology with behavior. Trends Cognit. Sci. $11,118-125$.

Bratt, J. D. (1998). Abraham Kuyper: A Centennial Reader. Grand Rapids, MI: Eerdmans.

Chun, M. M., and Potter, M. C. (1995). A two-stage model for multiple target detection in rapid serial visual presentation. J. Exp. Psychol. Hum. Percept. Perform. 21, 109-127.

Colzato, L. S., Bajo, M. T., van den Wildenberg, W., Paolieri, D., Nieuwenhuis, S. T., La Heij, W., and Hommel, B. (2008a). How does bilingualism improve executive control? A comparison of active and reactive inhibition mechanisms. J. Exp. Psychol. Learn. Mem. Cognit. 34, 302-312.
Colzato, L. S., Slagter, H. A., Spapè, M., and Hommel, B. (2008b). Blinks of the eye predict blinks of the mind. Neuropsychologia 46, 3179-3183.

Colzato, L. S., van den Wildenberg, W., and Hommel, B. (2008c). Losing the big picture: how religion controls visual attention. PLoS One 3: e3679. doi:10.1371/journal.pone.0003679.

Colzato, L. S., Spapè, M., Pannebakker, M., and Hommel, B. (2007). Working memory and the attentional blink: blink size is predicted by individual differences in operation span. Psychonomic Bull. Rev. 14, 1051-1057.

Colzato, L. S., van Beest, I., van den Wildenberg, W., Scorolli, C., Borghi, A. M., Dorchin, S., Meiran, N., and Hommel, B. (in press). God: do I have your attention? Cognition.

Colzato, L. S., van Hooidonk, L., van den Wildenberg, W. P. M., Harinck, F., and Hommel, B. (2010). Sexual orientation biases attentional control: a possible gaydar mechanism. Front. Psychol. 1: 13. doi:10.3389/ fpsyg.2010.00013.

Dale, G., and Arnell, K. M. (2010). Individual differences in dispositional focus of attention predict attentional blink magnitude. Atten. Percept. Psychophys. 72, 602-606.

Di Lollo, V., Kawahara, J. I., Ghorashi, S. M., and Enns, J. T. (2005). The attentional blink: resource depletion or

example, one could argue that Calvinism is more attractive for people with a more narrow allocation of attention, so that the findings may reflect mere self-selection. However, at least two counterarguments undermine, or at least question this possibility. First, people commonly join religious groups long before attentional or other biases become obvious (often by birth, following family traditions), which makes self-selection relatively unlikely. Second, we suggest a strong association between religious practice and attentional control given that we controlled for, and thus ruled out, group differences with respect to intelligence, age, mood, several personality traits, educational style, cultural background, and socio-economic status.

We thus take our findings to support the contention that religious practice has a measurable impact on attentional control as measured by the attentional blink paradigm. Interestingly, there is no reason to limit possible impacts to religion. As implied by Nisbett and Miyamoto (2005), any kind of practice that reflects particular rules or beliefs may have the potential to induce systematic biases. This includes cultural influences as well as membership of political parties or of particular minorities - as suggested by the recent observation that homosexual individuals exhibit a reduced global precedence effect (Colzato et al., 2010).

\section{ACKNOWLEDGMENT}

The research of Lorenza S. Colzato is supported by NWO (Netherlands Organization for Scientific Research).

temporary loss of control? Psychol. Res. 69, 191-200.

Dux, P. E., and Marois, R. (2009). The attentional blink: a review of data and theory. Atten. Percept. Psychophys. 71, 1683-1700.

Eysenck, S. B. G., Eysenck, H. J., and Barrett, P. (1985). A revised version of the psychoticism scale. Pers. Individ. Dif. 6, 21-29.

Gross, J., Schmitz, F., Schnitzler, I., Kessler, K., Shapiro, K., Hommel, B., and Schnitzler, A. (2006). Anticipatory control of long-range phase synchronization. Eur. J. Neurosci. 24, 2057-2060.

Hebb, D. O. (1949). The Organization of Behavior. New York: Wiley.

Hofstede,G.(2001).Culture's Consequences, Comparing Values, Behaviors, Institutions, and Organizations Across Nations. Thousand Oaks, CA: Sage Publications.

Hommel, B., and Colzato, L. S. (2010). Religion as a control guide: on the impact of religion on cognition. Zygon: J. Rel. Sci. 45, 596-604.

Hommel, B., Kessler, K., Schmitz, F., Gross, J., Akyürek, E., Shapiro, K., and Schnitzler, A. (2005). How the brain blinks: towards a neurocognitive model of the attentional blink. Psychol. Res. 70, 425-435.

Jefferies, L. N., Smilek, D., Eich, E. and Enns, J. T. (2008). Emotional valence and arousal interact in the control of attention. Psychol. Sci. 19, 290-295.

Jolicoeur, P., and Dell'Acqua, R. (1998). The demonstration of short-term consolidation. Cogn. Psychol. 36, 138-202.

Kossowksa, M., and Necka, E. (1994). Do it your own way: cognitive strategies, intelligence, and personality. Pers. Individ. Dif. 16, 33-46.

Martens, S., Elmallah, K., London, R., and Johnson, A. (2006a). Cuing and stimulus effects on the P3 and the AB. Acta Psychol. (Amst) 123, 204-218.

Martens, S., Munneke, J., Smid, H., and Johnson, A. (2006b). Quick minds don't blink: electrophysiological correlates of individual differences in attentional selection. J. Cogn. Neurosci. 18, 1423-1438.

Martens, S., and Johnson, A. (2005). Timing attention: cuing target onset interval attenuates the attentional blink. Mem. Cognit. 33, 234-240.

Martens, S., and Valchev, N. (2009). Individual differences in the attentional blink: the important role of irrelevant information. Exp. Psychol. 56, 18-26.

Masuda, T., and Nisbett, R. E. (2001). Attending holistically vs. analytically: comparing the context sensitivity of Japanese and Americans. J. Pers. Soc. Psychol. 81, 922-934.

McCullough, M. E., and Willoughby, B. L. B. (2009). Religion, self-control, and 
self-regulation: associations, explanations, and implications. Psychol. Bull. 135, 69-93.

Navon, D. (1977). Forest before trees. The precedence of global features in visual perception. Cogn. Psychol. 9, 353-383.

Nisbett, R. E., and Masuda, T. (2003). Culture and point of view. Proc. Natl. Acad. Sci. U.S.A. 100, 11163-11170.

Nisbett, R. E., and Miyamoto, Y. (2005). The influence of culture: holistic versus analytic perception. Trends Cogn. Sci. (Regul. Ed.) 9, 467-473.

Olivers, C. N. L., and Nieuwenhuis, S. T. (2005). The beneficial effect of concurrent task-irrelevant mental activity on temporal attention. Psychol. Sci. 16, 265-269.

Olivers, C. N. L., and Nieuwenhuis, S. (2006). The beneficial effects of additional task load, positive affect, and instruction on the attentional blink.
J. Exp. Psychol. Hum. Percept. Perform. 32, 364-379.

Potter, M. C., Staub, A., and O'Connor, D. H. (2002). The time course of competition for attention: attention is initially labile. J. Exp. Psychol. Hum. Percept. Perform. 28, 1149-1162.

Raven, J. C., Court, J. H., and Raven, J. (1988). Manual for Raven's Progressive Matrices and Vocabulary Scales. London: Lewis.

Raymond, J. E., Shapiro, K. L., and Arnell, K. M. (1992). Temporary suppression of visual processing in an RSVP task: an attentional blink? J. Exp. Psychol. Hum. Percept. Perform. 18, 849-860.

Shapiro, K., Schmitz, F., Martens, S., Hommel, B., and Schnitzler,A. (2006). Resource sharing in the attentional blink. Neuroreport 17, 163-166.

Slagter, H. A., Lutz, A., Greischar, L. L., Francis, A. D., Nieuwenhuis, S., Davis, J.
M., and Davidson, R. J. (2007). Mental training affects distribution of limited brain resources. PLoS Biol. 5: e138. doi:10.1371/journal.pbio.0050138.

Taatgen, N. A., Juvina, I., Schipper, M., Borst, J., and Martens, S. (2009). Too much control can hurt: a threaded cognition model of the attentional blink. Cogn. Psychol. 59, 1-29.

Visser, T., Bischof, W. F., and Di Lollo, V. (1999). Attentional switching in spatial and non-spatial domains: evidence from the attentional blink. Psychol. Bull. 125, 458-469.

Vogel, E. K., Luck, S. J., and Shapiro, K. L. (1998). Electrophysiological evidence for a postperceptual locus of suppression during the attentional blink. J. Exp. Psychol. Hum. Percept. Perform. 24, 1656-1674.

Conflict of Interest Statement: The authors declare that the research was con- ducted in the absence of any commercial or financial relationships that could be construed as a potential conflict of interest.

Received: 21 May 2010; paper pending published: 27 June 2010; accepted: 13 August 2010; published online: 01 September 2010. Citation: Colzato LS, Hommel B and Shapiro KL (2010) Religion and the attentional blink: depth of faith predicts depth of the blink. Front. Psychology 1:147. doi: 10.3389/fpsyg.2010.00147

This article was submitted to Frontiers in Cognition, a specialty of Frontiers in Psychology.

Copyright (c) 2010 Colzato, Hommel and Shapiro. This is an open-access article subject to an exclusive license agreement between the authors and the Frontiers Research Foundation, which permits unrestricted use, distribution, and reproduction in any medium, provided the original authors and source are credited. 